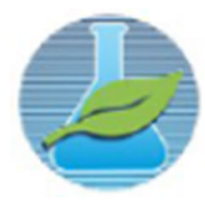

ol. 02 N. 04 (2016) 013-015
$\mathrm{JCEC} / \mathrm{REQ} \mathbf{Q}^{2}$

Journal

ISSN: 2446-9416

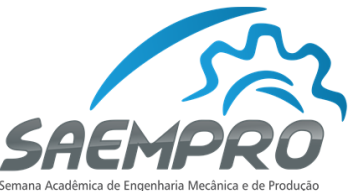

"EU, A INDÚSTRIA E O MUNDO"

08 a 11 de novembro de 2016 no campus Viçosa da UFV

Departamento de Engenharia de Produção e Mecânica - DEP

Universidade Federal de Viçosa - UFV

\title{
PROJETO DE UM SISTEMA PNEUMÁTICO DE CORTAR TUBOS DE PVC EM UMA LINHA DE PRODUÇÃO
}

\author{
Michel Ângelo de Rezende Coronel, Thiago Ferreira Martins \\ Universidade Federal de Viçosa, Departamento de Engenharia de Produção e Mecânica \\ $\mathrm{Ph}$. Rolfs s/n - 36570-900 - Viçosa - MG \\ michel.coronel@ufv.br, thiago.martins@ufv.br
}

\section{INTRODUÇÃO}

Esse trabalho consistiu em usar os conhecimentos teóricos da matéria Sistemas de Controle Hidráulicos e Pneumáticos para o desenvolvimento de um pneumático, de forma a automatizar um processo. Para a realização, foi feita a escolha de um processo específico, modelagem de redutores de tubulação, para ser automatizado. Concluiu-se que um sistema pneumático demonstrou ser a melhor opção para esse problema, pois as pressões demandadas são relativamente baixas.

\section{OBJETIVOS}

O projeto tem como finalidade a modelagem de redutores de tubulação através de um sistema pneumático automatizado.

\section{METODOLOGIA}

Foi idealizado um processo que conta com quatro cilindros pneumáticos, cada qual com uma função específica. Considerou-se que as perdas de carga devido as tubulações e outros componentes do sistema são desprezíveis devido à baixa viscosidade do ar. Para modelar o sistema foi usado o software da FESTO FluidSIM ${ }^{\circledR}$ pneumático. Os componentes do dispositivo são: os cilindros já citados, uma mesa, uma máquina de corte, um estampador, um fixador com formato a modo de prender o tubo de PVC, a tubulação pneumática e o compressor. Algumas considerações iniciais foram realizadas para os cálculos e são determinadas pela Tab. 1 .

Tabela 1 - Considerações iniciais.

\begin{tabular}{|c|c|}
\hline Pressão do compressor & $1 \mathrm{MPa}$ \\
\hline Aceleração gravitacional & $9,81 \mathrm{~m} / \mathrm{s}^{2}$ \\
\hline
\end{tabular}

Como já citado, cada cilindro possui uma função que será explicitada na Tab. 2:

Tabela 2 - Funções de cada cilindro.

\begin{tabular}{|c|c|}
\hline Cilindro & Função \\
\hline A & Deslocamento da mesa superior \\
\hline B & Deslocamento da estampagem \\
\hline C & Deslocamento do molde \\
\hline D & Deslocamento da máquina de corte \\
\hline
\end{tabular}

As velocidades de operação também foram pré-definidas, como podem ser vistas na Tab. 3: 
Tabela 3 - Velocidade de operação do sistema.

\begin{tabular}{|c|c|c|c|c|}
\hline Cilindro & $\begin{array}{c}\text { Velocidade - Parte } \\
\text { 1 do ciclo }\end{array}$ & $\begin{array}{c}\text { Velocidade - Parte } \\
\text { 2 do ciclo }\end{array}$ & Curso (mm) & Massa (kg) \\
\hline A & 0,01 & 0,01 & 76,2 & 8,396 \\
\hline B & 0,05 & 0,14 & 76,2 & 0,250 \\
\hline C & 0,02 & 0,06 & 320 & - \\
\hline D & 0,03 & 0,05 & 200 & - \\
\hline
\end{tabular}

Um dos princípios idealizados é que o projeto além de acadêmico seja comercial. Portanto o processo como um todo respeita uma lógica organizacional industrial. Por causa disso todos os componentes do sistema estão em catálogos comerciais de empresas e a velocidade é adequada para uma fabricação real.

Tendo esses princípios em mente, uma sequência foi desenvolvida para atender os conceitos. $\mathrm{O}$ tubo chega ao suporte inferior de fixação através de uma esteira, previamente preparado para a modelagem. O sistema é, então, acionado e o suporte superior se desloca para baixo, a fim de estabilizar o tubo a ser moldado. Em seguida, os cilindros de estampagem, moldagem e corte são ativados, realizam suas funções e retornam à posição inicial, respectivamente, como representado na Fig. 1.

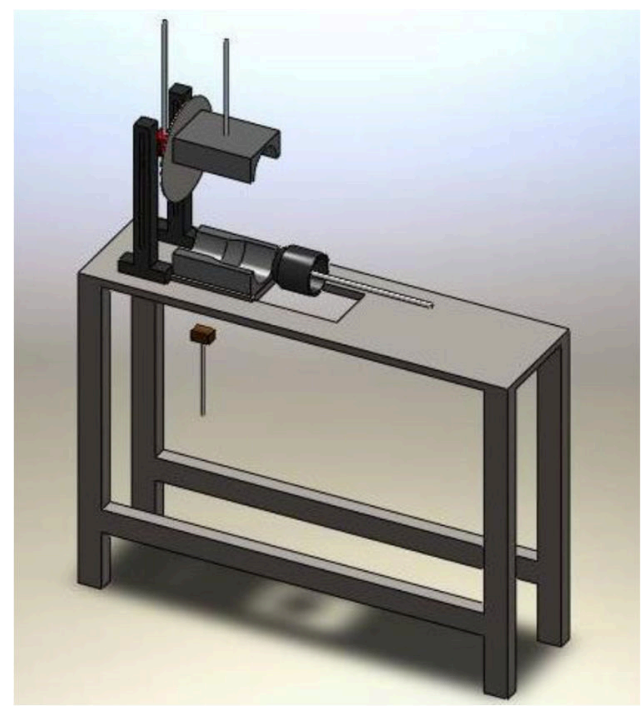

Figura 1 - Representação do projeto (autores).

Além dos cálculos de balanceamento de força, de pressão nos componentes pneumáticos e de vazão, foram executados cálculos estruturais de flambagem das hastes dos cilindros que estão sofrendo compressão que são regidas pela Eq. (1) e pela Eq. (2).

$L f=\frac{1}{2} \sqrt{\frac{\pi^{3} E m D^{4}}{224 f t}}$

$C=\frac{L f}{2}$

A Eq. (1) é para cálculo do comprimento de flambagem de um eixo circular de diâmetro $D$, feito de um material com módulo de elasticidade $E m$ sujeito a uma força F. Fté obtida multiplicando pelo coeficiente de segurança, igual a 3,5. Já a Eq. (2) é para uma extremidade livre e outra engastada, o comprimento da peça deve ser metade do comprimento de flambagem.

\section{RESULTADOS}


Utilizando o software EES $^{\circledR}$ para os devidos cálculos, definidas as velocidades na Tab. 3, calculou-se o valor teórico das vazões em cada atuador. Após a montagem do circuito no FluidSIM ${ }^{\circledR}$, comparou-se os valores calculados com os valores obtidos no programa. Os valores foram bem semelhantes, a maior diferença percentual foi no cilindro D, no valor $23,37 \%$. Enquanto a menor discrepância percentual foi no cilindro A, com o valor de $2,640 \%$. Isso se deve a algumas aproximações que ambos os programas fazem ao processar as informações.

\section{CONCLUSÕES}

Após os cálculos serem feitos, com auxílio do software EES ${ }^{\circledR}$ (Engineering Equation Solver), e as simulações no FluidSIM ${ }^{\circledR}$ verificou-se que o invento funciona na ordem pré-determinada, com a velocidade de produção pretendida, sem flambagem nas hastes dos cilindros e sem pressão negativa no sistema. Portanto, faltou apenas uma análise profunda dos detalhes construtivos e como funcionaria em uma linha de produção de redutores para saber se o protótipo é economicamente viável e comercial.

\section{AGRADECIMENTOS}

Agradecemos especialmente ao Lucas de Oliveira Barbosa, Diogo de Souza Tomazini e ao Aron Ferreira Milagres por terem contribuído imensamente para a realização do trabalho, eles foram fundamentais.

\section{REFERÊNCIAS}

SILVA, E.C.N. “Apostila de Pneumática”. USP. São Paulo, 2002.

FIALHO, A.B. “Automação Pneumática”. 7 ed. São Paulo, 2013.

LINSINGEN, I.V. "Fundamentos de Sistemas Hidráulicos”. 2 ed. Florianópolis: UFSC. 2008. 